Differential repair of DNA damage in specific nucleotide sequences in monkey cells

Steven A.Leadon*

Department of Biological Sciences, Stanford University, Stanford, CA 94305, USA

Received 25 June 1986; Revised and Accepted 18 October 1986

\begin{abstract}
An immunological method was developed that isolates DNA fragments containing bromouracil in repair patches from unrepaired DNA using a monoclonal antibody that recognizes bromouracil. Cultured monkey cells were exposed to either UV light or the activated carcinogen aflatoxin $B$ and excision repair of damage in DNA fragments containing the integrated and transcribed E.coli gpt gene was compared to that in the genome overall. A more rapid repair of both UV and AFB damage was observed in the DNA fragments containing the E.coli gpt genes. The more efficient repair of UV damage was not due to a difference in the initial level of pyrimidine dimers as determined with a specific UV endonuclease. Consistent with previous observations using different methodology, repair of UV damage in the alpha sequences was found to occur at the same rate as that in the genome overall, while repair of AFB damage was deficient in alpha DNA. The preferential repair of damage in the gpt gene may be related to the functional state of the sequence and/or to alterations produced in the chromatin conformation by the integration of plasmid sequences carrying the gene.
\end{abstract}

\title{
INTRODUCTION
}

It is of increasing interest and significance to ascertain whether or not all sequences in the eucaryotic genome are damaged and repaired to the same extent. It is known that the chromatin structure both of expressed genes and of the sites of integration of foreign DNA cause these sequences to be highly sensitive to digestion by DNAse I $(1,2,3)$, while non-expressed, tandemly repeated DNA sequences exist in tightly condensed chromatin structures (4). We are just beginning to learn to what extent these different chromatin structures affect the distribution of damage and repair in the genome. Lesions produced by aflatoxin $B_{1}\left(A_{1} B_{1}\right)(5,6)$, furocoumarins $(7,8,9)$, and $\mathrm{N}$-acetoxy-2-acetyl aminofluorene (10) are found predominantly in the internucleosomal linker DNA. Studies with the highly repetitive alpha DNA of African green monkey cells have shown that removal of certain bulky chemical adducts from the heterochromatic, non-transcribed alpha DNA is less efficient than is their removal from the genome overall (11-14). Evidence has been 
presented for preferential binding of $A_{1} B_{1}$ to ribosomal genes (15), for preferential binding and removal of benzo(a)pyrene in the transcribed fraction of the genome (16) and for more rapid removal of pyrimidine dimers from the highly amplified dihydrofolate reductase gene in Chinese hamster ovary cells (17). However, the formation and repair of alkali labile sites induced by $N$-methyl-N'-nitro-N-nitrosoguanidine was similar in the transcriptionally active collagen type $I$ gene and inactive $\beta$-globin gene of human cells (18). Thus, the biological consequences of DNA damage and the mode of its repair probably depend upon the type of damage introduced into the DNA and upon the functional state of the chromatin where the damage is located.

In this study, we have developed an immunological method for the measurement of repair, similar to that described by Cohn and Lieberman $(19,20)$, using a monoclonal antibody to bromouracil-containing DNA to separate DNA fragments containing repair patches from unrepaired DNA. The presence of specific sequences in the repaired and unrepaired DNA fragments are detected by using nick translated probes for the sequences of interest. Unlike methods which rely upon the loss of a labeled adduct or of an endonuclease sensitive site from a sequence, this technique sensitively detects the repair synthesis event itself and therefore allows direct comparison of repair in specific sequences of a variety of types of DNA damage. We have applied this method to the question of whether the repair of damage in a region of the genome that contains an integrated and expressed foreign DNA is different from that in the genome overall. A comparison was made between the overall rate of repair synthesis following UV irradiation or treatment with $\mathrm{AFB}_{1}$ and the rate of repair in regions of the monkey genome containing the integrated and transcribed gpt gene of E.coli (Ecogpt). A more rapid repair of both UV and $A_{F B}$ damage was observed in DNA fragments containing the Ecogpt gene than in the genome overall. We also employed the immunological method to measure repair in DNA fragments containing the alpha DNA sequence, since repair in this sequence in monkey cells has been extensively characterized (11-14). Consistent with the previous observations measuring repair synthesis and direct adduct removal, repair of UV damage in alpha DNA occured at the same rate as that in the genome overall, while repair of $\mathrm{AFB}_{1}$ damage was deficient in alpha $\mathrm{DNA}$. The rapid repair of damage in the Ecogpt gene may be related to the functional state of the sequence and/or to alterations produced in the chromatin conformation by the integration of plasmid sequences carrying the gene. 
MATERIALS AND METHODS

Cell Culture Conditions and Treatment.

CV-1 African green monkey cells containing the plasmid pSV2-gpt were obtained from J. Reichardt and P. Berg (Stanford University). The number of copies of the plasmid integrated into the monkey genome was determined by slot blotting onto nitrocellulose filters serial dilutions of the genomic DNA from the monkey cells and known amounts of pSV2-gpt to serve as standards. The presence of the plasmid was detected by hydridizing the filters with ${ }^{32} \mathrm{p}$-nick translated pSV2-gpt as described below. Following autoradiography, the intensity of the hybridization was quantitated by densitometry. Approximately 3 copies of pSV2-gpt were present in the cell line. The organization of these sequences within the chromosomal DNA was determined by digesting genomic DNA with restriction enzymes that cut once within the pSV2-gpt sequence (Hind III or Bam HI) or do not cut within the sequence (Xho I). The DNA was electrophoresed on neutral $0.7 \%$ agarose gels, transferred to nitrocellulose filters, hybridized with pSV2-gpt as probe and autoradiographed as described below. Digestion of the DNA with Xho I produced a single restriction fragment (approximately $25 \mathrm{~kb}$ ) containing pSV2-gpt, while digestion of the DNA with either Hind III or Bam HI produced 3 restriction frayments containing pSV2-gpt, one of which corresponded to the size of the plasmid $(5.3 \mathrm{~kb})$. This pattern indicates that the 3 copies of pSV2-ypt are arranged tandemly. Expression of the Ecogpt gene, which codes for xanthine-guanine phosphoribosyltransferase, was maintained by growing the cells in selective medium containing mycophenolic acid, methotrexate, xanthine, hypoxanthine and thymidine (21). For prelabeling of DNA, cells were grown for 7 days in either $1 \mathrm{uCi} / \mathrm{ml}\left[{ }^{3} \mathrm{H}\right]$ thymidine or $0.15 \mathrm{uCi} / \mathrm{ml}$ $\left[{ }^{14} \mathrm{C}\right]$ thymidine (New England Nuclear). These cells were pooled, subcultured at a ratio of $1: 3$ in nonradioactive medium and were used for experiments $7-9$ days later. Confluent cultures of either ${ }^{3} \mathrm{H}$ - or ${ }^{14} \mathrm{C}-1$ abeled cells were irradiated at $254 \mathrm{~mm}$ using a Westinghouse IL 782-30 germicidal 1 amp at an incident dose rate of $0.33 \mathrm{~J} / \mathrm{m}^{2} / \mathrm{s}$, which produces 2.4 pyrimidine dimers per $10^{8}$ daltons DNA per $\mathrm{J} / \mathrm{m}^{2}$ in cultured cells (22), or were exposed to $0.32 \mathrm{mM}$ $\mathrm{AFB}_{1}$ (Calbiochem-Behring) in the presence of an activation buffer containing S9 microsomes for $60 \mathrm{~min}$ at $37^{\circ} \mathrm{C}(11,23)$. After exposure to the DNA damaging agents, the cultures were incubated at $37^{\circ} \mathrm{C}$ for various lengths of time in selective medium containing $50 \mathrm{uM}$ bromodeoxyuridine (BrdUrd) instead of thymidine and with the serum concentration reduced to $0.2 \%$. In experiments where repair synthesis was measured, $30 \mathrm{uCi} / \mathrm{ml}\left[{ }^{3} \mathrm{H}\right]$ thymidine 
(72.5 Ci/nmol; New England Nuclear) was included in the selective medium. Cells used for determination of pyrimidine dimer frequencies were incubated in selective medium with $0.2 \%$ serum but without BrdUrd.

\section{DNA Isolation.}

Genomic DNA to be analyzed by gel electrophoresis was isolated on polycarbonate filters essentially as described by Leadon and Cerutti (24). The DNA was released from the filters with Xho I (Bethesda Research Laboratories; $5 \mathrm{U} / \mathrm{ug} \mathrm{DNA})$. Genomic DNA to be analyzed by slot hybridization was isolated from cells that were lysed, treated with proteinase $K$ directly on the culture dishes and sheared by two passages through a 25 gauge needle to an average molecular weight of $10^{7}$ daltons. With both procedures, the parental density DNA (containing bromouracil (BrUra)-substituted repair patches) was resolved from hybrid density DNA (synthesized by semiconservative replication) on $\mathrm{CsCl}$ gradients (25). The parental density DNA was then dialyzed extensively against $10 \mathrm{mM}$ Tris, $\mathrm{pH}$ 8, to remove the $\mathrm{CsCl}$.

Separation of DNA Fragments Containing Repair Patches.

DNA was reacted with a monoclonal antibody against BrUra (generously supplied by M. Vanderlaans and J. Gray, Lawrence Livermore Laboratory; 26) by a modification of the procedure described by Aarden et al. (27). 20 ug of heat denatured DNA was incubated with 30 ug antibody in phosphate buffered saline (PBS) containing $0.1 \%$ bovine serum albumin for $1 \mathrm{~h}$ at $37^{\circ} \mathrm{C}$. An equal volume of ice-cold saturated ammonium sulphate in PBS was added and the incubation continued for $15 \mathrm{~min}$ at $4^{\circ} \mathrm{C}$. The precipitate was collected by centrifugation for $10 \mathrm{~min}$ in a Beckman microfuge $B$ at $4^{\circ} \mathrm{C}$. The supernatant was carefully removed and the pellet dissolved in double distilled water. Aliquots of the supernatant and pellet were assayed for radioactivity by liquid scintillation counting to determine the relative amount of DNA bound by the antibody.

Equal amounts of DNA from the supernatant and pellet were electrophoresed on $0.5 \%$ alkaline agarose gels as described by Bohr et al. (16). The DNA was transferred to Zetabind membranes (AMF) as described by Southern (28) and Wahl et al. (29). The membranes were prehybridized in $5 \times$ SSPE (SSPE $=100 \mathrm{mM}$ $\mathrm{NaCl}, 10 \mathrm{mM} \mathrm{NaPO} 4$ (pH 7.8), $1 \mathrm{mM}$ EDTA), 10x Denhardt's solution, $500 \mathrm{ug} / \mathrm{ml}$ sonicated denatured salmon sperm DNA and $50 \%$ formamide for $4 \mathrm{~h}$ at $42^{\circ} \mathrm{C}$, then hybridized with ${ }^{32}$ p-nick translated pSV2-gpt in 5x SSPE, 1x Denhardt's, 100 $\mathrm{ug} / \mathrm{ml}$ denatured salmon sperm DNA and $50 \%$ formamide for $16 \mathrm{~h}$ at $42^{\circ} \mathrm{C}$. Unbound probe was removed by washing the membranes twice in $2 x$ SSPE, $0.1 \%$ sodium dodecyl sulphate (SDS) for $15 \mathrm{~min}$ at room temperature and twice in $2 \mathrm{x}$ 
SSPE, $0.1 \%$ SDS for 30 min at $60^{\circ} \mathrm{C}$. Following autoradiography, the initial hybridized probe was removed by incubating the membranes in $0.4 \mathrm{~N} \mathrm{NaOH}$ for 30 min at $42^{\circ} \mathrm{C}$. The membranes were prehybridized for $16 \mathrm{~h}$ at $42^{\circ} \mathrm{C}$ prior to hybridization with ${ }^{32}$ p-nick translated alpha probe (a 340 bp dimer of alpha DNA isolated from PCA1004a provided by M. Singer, NIH; 30) as described above.

For analysis by slot hybridization, the DNA from the supernatant and pellet were denatured by the addition of $1 / 10$ volume $3 \mathrm{~N} \mathrm{NaOH}$ and incubation at $80^{\circ} \mathrm{C}$ for $10 \mathrm{~min}$. The samples were neutralized with an equal volume of 2 $M$ ammonium acetate and slot blotted in duplicate onto nitrocellulose filters. The filters were prehybridized in $5 x$ SSPE, $0.5 \%$ SDS, $5 x$ Denhardt's solution and $100 \mathrm{ug} / \mathrm{ml}$ denatured salmon sperm DNA for $2-4 \mathrm{~h}$ at $68^{\circ} \mathrm{C}$ and hybridized in a solution with the same composition except that the final concentration of Denhardt's solution was reduced to $2 x$. Hybridization was allowed to proceed for $16 \mathrm{~h}$ at $68^{\circ} \mathrm{C}$. The filters were washed twice in $2 x$ SSPE, $0.1 \%$ SDS for 30 min at $50^{\circ}$ C. Autoradiography was carried out using Kodak XAR-5 and the intensity of the hybridization quantitated by densitometry.

\section{$\underline{T 4}$ endonuclease $\underline{v}$ treatment.}

Sites sensitive to the T4 endonuclease $V$ were determined essentially as described by Seawell et al. (31) and Bohr et al. (17). DNA samples with and without the endonuclease were incubated for $15 \mathrm{~min}$ at $37^{\circ} \mathrm{C}$. Equal amounts of DNA (usually $5 \mathrm{ug}$ ) were electrophoresed in duplicate on $0.7 \%$ alkaline agarose gels, transferred to nitrocellulose filters and treated as described above for the Zetabind membranes except that each half of the duplicate was hybridized with only a single probe.

\section{RESULTS}

Binding of the Antibody to DNA Containing Repair Patches.

Confluent cultures of $\mathrm{CV}-1$ cells were exposed to various doses of UV light and then incubated in selective medium containing Brdurd instead of thymidine. Fully hydrid density DNA made by semiconservative synthesis was separated from unreplicated DNA by centrifugation in $\mathrm{Cs} C l$ density gradients (25). Unreplicated, parental-density DNA was then reacted with a monoclonal antibody against BrUra and the DNA bound by the antibody was precipitated in 50\% ammonium sulfate and separated from free DNA by centrifugation (27). When cells were irradiated with UV followed by a $12 \mathrm{~h}$ post-treatment incubation, the percentage of DNA bound by the antibody increased linearly with dose up to $50 \mathrm{~J} / \mathrm{m}^{2}$ (Fig. 1). 


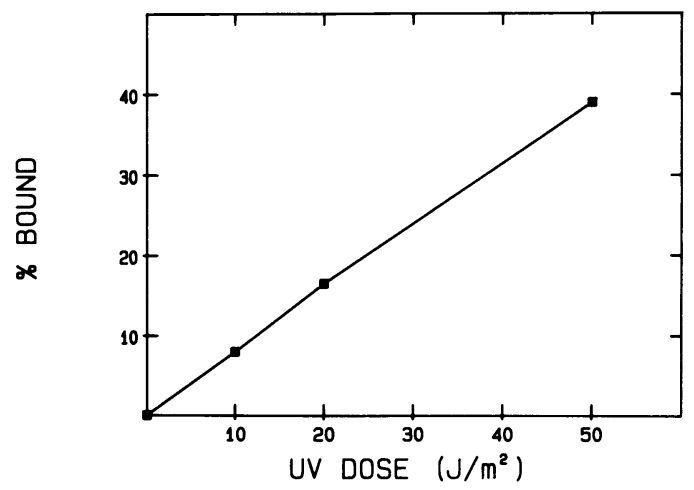

Figure 1. Percentage of DNA fragments bound by the antibody as a function of UV dose to the cell. CV-1 cultures, labeled with $\left[{ }^{3} \mathrm{H}\right]$ thymidine, were irradiated with various doses of UV light and incubated for $12 \mathrm{~h}$ in the presence of 50 uM BrdUrd. Parental density DNA was isolated from $\mathrm{CsCl}$ gradients and reacted with a monoclonal antibody against BrdUrd. DNA bound to the antibody was precipitated in 50\% ammonium sulphate and the percentage of DNA in the bound and free fractions determined by liquid scintillation.

The proportion of DNA fragments containing repair patches that reacted with the antibody was measured by labeling UV irradiated cells with $\left[{ }^{3} \mathrm{H}\right]-$ thymidine during the post-treatment incubation. The amount of total DNA (represented by the ${ }^{14} \mathrm{C}-1 \mathrm{abel}$ ) reacting with the antibody increased nearly linearly with time (Fig. 2). However, the percentage of DNA containing repair label which was bound by the antibody was approximately $70 \%$ at $6 \mathrm{~h}$ and $90 \%$ by $48 \mathrm{~h}$ post-treatment. When DNA from the $48 \mathrm{~h}$ post-UV incubation was sheared by sonication to an average of $200 \mathrm{bp}$, the amount of total DNA reacting with the antibody was substantially reduced from $80 \%$ to only $3-4 \%$, while the amount of DNA containing the repair label was not significantly reduced (data not shown). Thus, the accumulation of repair patches substituted with BrUra, produced by increasing either the initial amount of UV damage or the post-UV incubation, resulted in an increase in the amount of DNA bound by the antibody. In addition, a preferential binding of antibody to those DNA fragments containing repair patches was observed.

\section{Repair in Specific Sequences.}

Since the antibody reacted specifically with DNA containing repair patches substituted with BrUra, we examined whether specific DNA sequences might be preferentially found in the subset of DNA fragments having repaired regions. After separating DNA bound by the antibody from free DNA, equal amounts of DNA from the supernatant and pellet were either electrophoresed on 


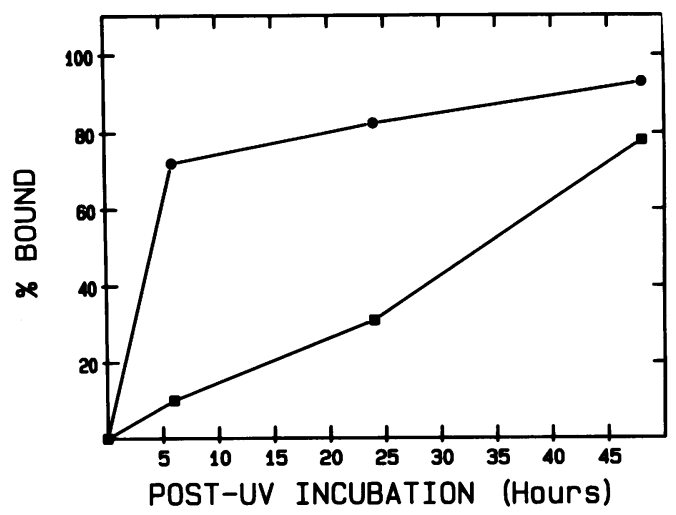

Figure 2. Percentage of DNA bound by the antibody as a function of postUV incubatign. Cell cultures, labeled with [ $\left.{ }^{4} \mathrm{C}\right]$ thymidine, were irradiated with $20 \mathrm{j} / \mathrm{m}^{2}$ UV light and incubated for various times in the presence of 30 $\mathrm{uCi} / \mathrm{ml}\left[{ }^{3} \mathrm{H}\right]$ thymidine and $50 \mathrm{uM}$ BrdUrd. Genomic DNA was prepared as described in Figure 1. The percentage of total DNA bound was determined from the mass label ( $\square$ ) and the percentage of DNA bound containing repair patches was determined from the repair label (O).

alkaline agarose gels and transferred to a membrane support or were slot blotted in duplicate directly onto nitrocellulose filters. The presence of specific DNA sequences in the bound and free fractions was detected by using ${ }^{32} \mathrm{p}-\mathrm{labeled}$ probes specific for the sequences of interest: the non-transcribed alpha sequence or the transcribed Ecogpt gene resident on the plasmid pSV2-gpt integrated as 3 tandemly arranged copies into the genome of these cells. Cells were exposed to either $20 \mathrm{~J} / \mathrm{m}^{2}$ UV light or $0.32 \mathrm{mM} \mathrm{AFB}$ and allowed to repair for $24 \mathrm{~h}$. The DNA was isolated and digested with the restriction endonuclease Xho I since neither pSV2-gpt or the alpha sequence contain Xho I sites. Because both sequences are tandemly arranged within the genome, the digestion produced unique sized restriction fragments that contained each sequence. The autoradiogram in Fig. 3 shows that for the same amount of DNA loaded into each lane of the gel $(0.5 \mathrm{ug})$, more hybridization to pSV2-gpt sequences was found in the fraction bound by the antibody (Fig. 3,1 anes $a$ and $c$ ) than in the free fractions ( 1 anes $b$ and $d$ ). When the same filter was probed for the presence of alpha sequences, similar amounts of hybridization to alpha sequences were found in the bound and free fractions following UV irradiation (Fig. 3, lanes $a^{\prime}$ and $\left.b^{\prime}\right)$. However, in cells treated with $A F B_{1}$, a decreased hybridization to alpha sequences was found in the fraction bound by the antibody ( 1 anes $c^{\prime}$ and $\left.d^{\prime}\right)$. For sequences with $a$ 


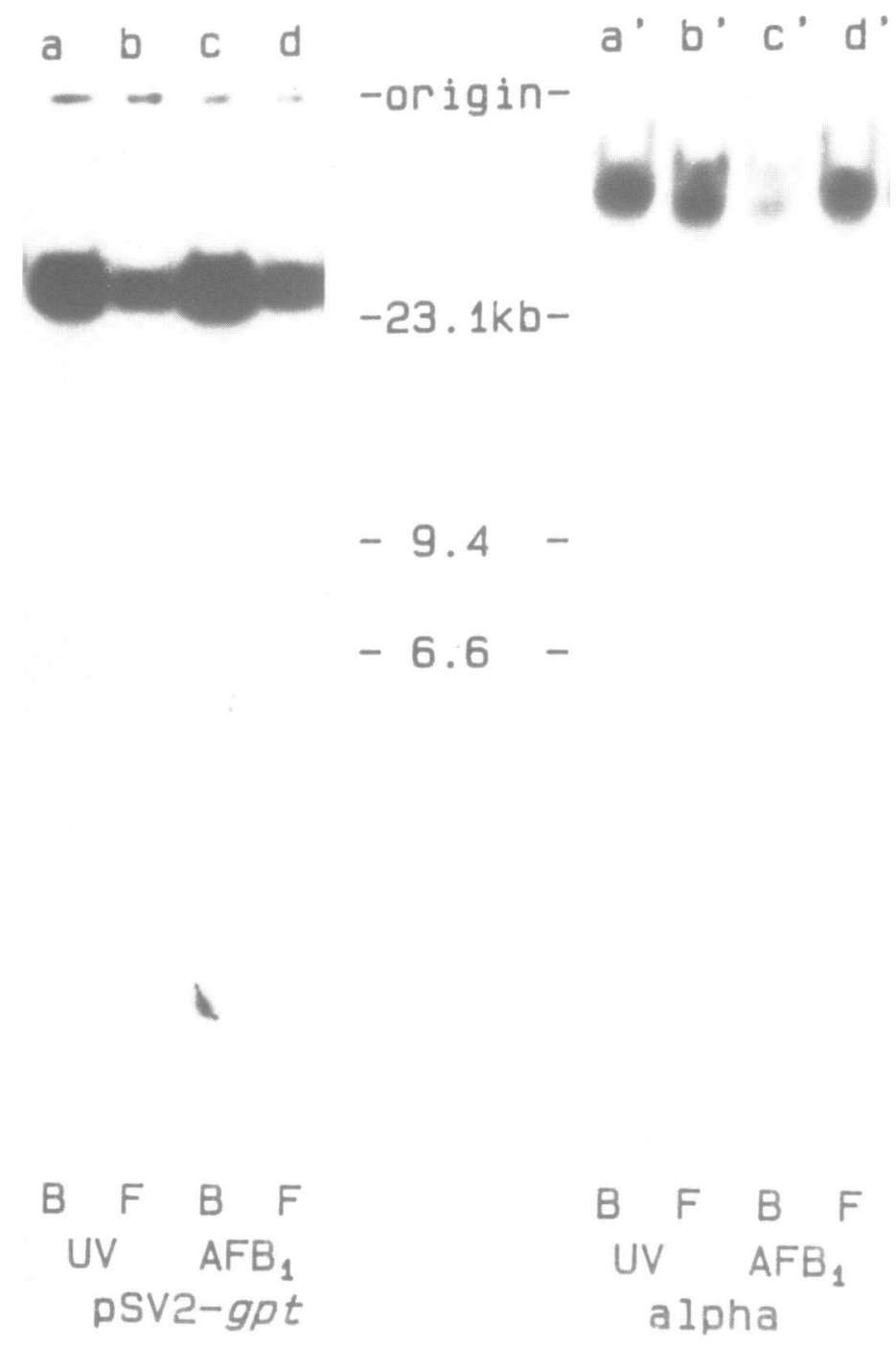

Figure 3. Hybridization of specific sequences to repaired DNA. Cell cultures were exposed to either $20 \mathrm{~J} / \mathrm{m}^{2}$ UV or $0.32 \mathrm{mM} \mathrm{AFB}$ and incubated for 24 $h$ in the presence of 50 uM BrdUrd. Genomic DNA, digested with Xho I, was reacted with the antibody to BrdUrd. DNA bound by the antibody was precipitated with $50 \%$ ammonium sulphate and $0.5 \mathrm{ug}$ from the bound (B) and free (F) fractions were electrophoresed on a $0.5 \%$ alkaline agarose ${ }_{3}$ el. The DNA was transferred to a Zetabind membrane and probed first with $32_{p-n i c k}$ translated pSV2-gpt ( 1 anes $a-d$ ) and then with a 340 bp alpha dimer ( 1 anes $\left.a^{\prime}-d^{\prime}\right)$. The origin and size markers are indicated. 
TABLE 1. The percentages of pSV2-gpt and alpha sequences present in DNA fraginents bound by the antibody following a $24 \mathrm{hr}$ post-treatment incubation.

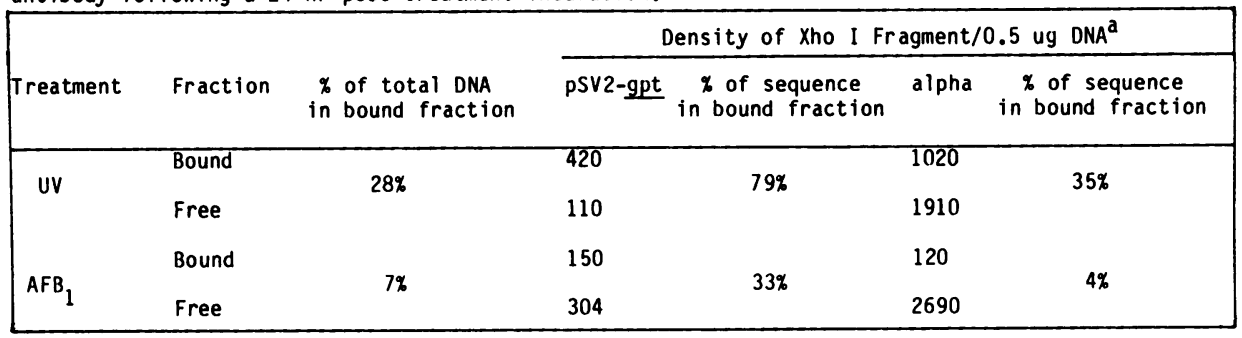

arbitrary units of optical density.

high degree of homology, the intensity of probe hybridized to a genomic restriction fragment reflects the amount of the sequence of interest present. The intensity of hybridization was quantitated by densitometry and the percentage of each sequence in the bound fraction per 0.5 ug of DNA loaded onto the gel was compared to the percentage of total DNA bound by the antibody (Table 1). A 3-4 fold enhancement was found in the percentage of the Ecogpt gene in the bound fraction after either UV or $A_{1 B}$ when compared to the total DNA bound by the antibody. This indicates that there are more repair patches in those DNA fragments which contain the Ecogpt gene. In contrast, the same percentage of the alpha sequence was found in the bound fraction as in the total amount of DNA bound by the antibody following UV irradiation. This indicates that there are, on average, the same number of repair patches in alpha DNA as in the rest of the genome. Following treatment with $A F B_{1}$, fewer alpha sequences were found in the bound fraction compared to the total amount of DNA bound by the antibody, indicating that there is a lower frequency of repair patches in alpha DNA compared to that in the rest of the genome.

The comparative time course for the repair of DNA damage in the Ecogpt gene and the alpha sequence was determined by blotting DNA from the bound and free fractions onto duplicate nitrocellulose filters and then hybridizing with probe made from either pSV2-gpt or the 340 bp dimer of alpha DNA. The amount of each sequence in the two fractions was quantitated by densitometry of the autoradiogram. Following irradiation of cells with $20 \mathrm{~J} / \mathrm{m}^{2}$, an increase in the percentage of both the Ecogpt and the alpha sequences in the DNA that was bound by the antibody was found with post-treatment incubation (Fig. 4). However, a higher percentage of the Ecogpt sequences were found in DNA fragments bound by antibody than there was total DNA bound by the 


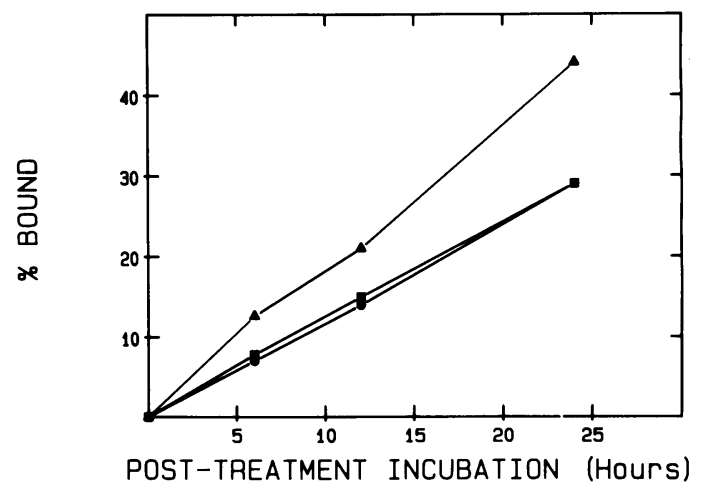

Figure 4. Repair of UV damage in specific nucleotide sequences. Cell cultures were irradiated with $20 \mathrm{~J} / \mathrm{m}^{2}$ and incubated for various times as described in the legend to Figure 1. Equal amounts of DNA from the bound and free fractions were slot blotted onto nitrocellulose in duplicate and probed with either ${ }^{2}$ p-nick translated pSV2-gpt or a 340 bp dimer of alpha DNA. The Bercentage of total DNA $(\boldsymbol{\square})$ bound by the antibody was determined from the ${ }_{\mathrm{H}} \mathrm{H}$-prelabel. The percentages of pSV2-gpt $(\boldsymbol{\Delta})$ and alpha sequences $(\boldsymbol{O})$ bound by the antibody was determined by densitometry of the autoradiograms.

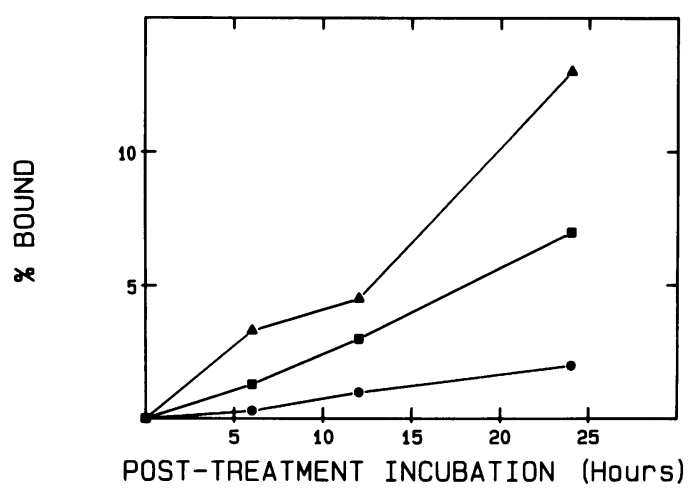

Figure 5. Repair of $A F B$ damage in specific nucleotide sequences. Cell cultures were exposed to $0.32 \mathrm{mM} A F B$ and incubated for various times as described in the legend to Figure 1. Equal amounts of DNA from the bound and free fractions were slot blotted onto nitrocellulose and probed for either PSV2-gpt or a 340 bp dimer of alpha DNA. The percentages of total DNA $(\square)$, pSV2-gpt (A) and alpha sequences (O) were determined as described for figure 4.

antibody, while the percentage of alpha sequences in the antibody-bound DNA fragments was similar to total DNA. Similar results were found if the cells were irradiated with only $10 \mathrm{~J} / \mathrm{m}^{2}$ (data not shown). Thus, the regions of the genome with the repair sites preferentially contain the Ecogpt genes. 


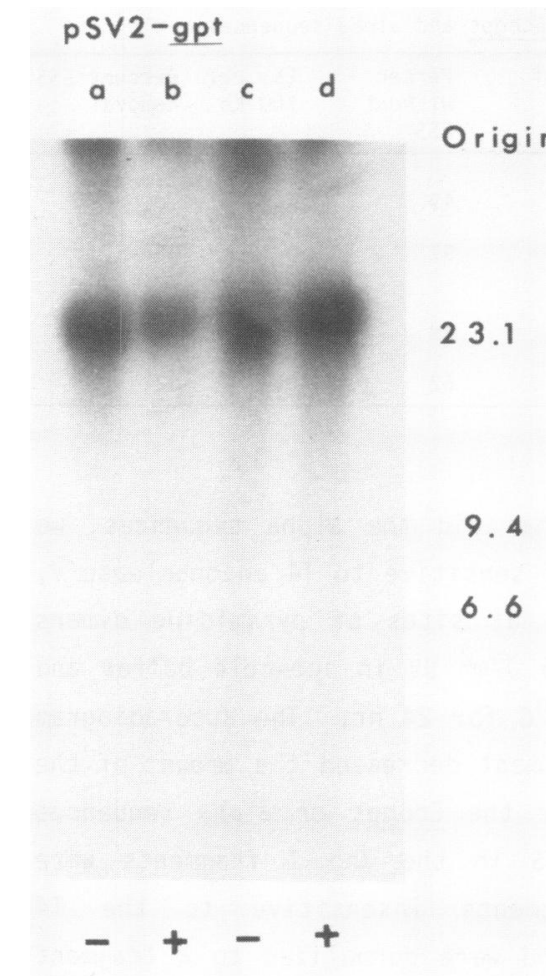

\section{A L PHA}

a $\quad b \quad c \quad d$

Figure 6. Formation and removal of ESS in the Ecogpt and alpha sequences. DNA prepared from cells irradiated with $5 \mathrm{~J} / \mathrm{m}^{2}$ was restricted with Xho I, treated (+) or not (-) with T4 endonuclease, electrophoresed, transferred to nitrocellulose filter and hybridized to either nick-translated pSV2-gpt or a 340 bp dimer of alpha DNA. Lanes $a$ and $b$ contain DNA from cells that were lysed immediately after irradiation; lanes $c$ and $d$ contain DNA from cells given a $24 \mathrm{~h}$ post-irradiation incubation. The origin and size markers are indicated.

Similarly, following exposure of cell cultures to activated $A_{F} B_{1}$, a higher percentage of the Ecogpt sequences was found in the DNA bound by the antibody with post-treatment incubation than total antibody-bound DNA (Fig. 5). In contrast, a much lower percentage of the alpha sequences were in the DNA fragments bound by the antibody than total DNA. Therefore, in the regions of the genome in which repair had taken place following exposure to $A_{F B}$, there was a higher frequency of repair patches found in those regions containing the Ecogpt genes than in the genome overall and relatively few repair patches in those regions containing the alpha sequences.

Initial Frequencies and Removal of Endonuclease Sensitive Sites (ESS).

To determine if the regions of the genome with the Ecogpt genes contained 
TABLE 2. Initial frequencies and removal of ESS from Ecogpt and alpha sequences.

\begin{tabular}{|c|c|c|c|c|c|c|}
\hline Sequence & $\begin{array}{l}\text { Repair } \\
\text { Period, } \\
h\end{array}$ & Endonuclease & $\begin{array}{l}\text { Density of } \\
\text { Xho I } \\
\text { Fragment }\end{array}$ & $\begin{array}{l}\text { Percent } \\
\text { without } \\
\text { ESS }\end{array}$ & $\begin{array}{l}\text { Ess per } \\
100 \mathrm{~Kb}\end{array}$ & $\begin{array}{l}\text { Percent ESS } \\
\text { Removal }\end{array}$ \\
\hline Ecogpt & $\begin{array}{l}0 \\
0 \\
24 \\
24\end{array}$ & $\begin{array}{l}- \\
+ \\
+\end{array}$ & $\begin{array}{r}1270 \\
620 \\
1160 \\
1120\end{array}$ & $\begin{array}{l}49 \\
97\end{array}$ & $\begin{array}{l}2.85 \\
0.12\end{array}$ & 96 \\
\hline Alpha & $\begin{array}{l}0 \\
0 \\
24 \\
24\end{array}$ & $\begin{array}{l}- \\
+ \\
+\end{array}$ & $\begin{array}{r}1490 \\
430 \\
1460 \\
910\end{array}$ & $\begin{array}{l}29 \\
62\end{array}$ & $\begin{array}{l}2.5 \\
0.95\end{array}$ & 62 \\
\hline
\end{tabular}

arbitrary units of optical density.

a different initial frequency of damage than did the alpha sequences, we measured changes in the frequencies of sites sensitive to T4 endonuclease $V$, which makes single-strand scissions in DNA at sites of pyrimidine dimers (32). Cell cultures were irradiated with $5 \mathrm{~J} / \mathrm{m}^{2}$ UV in ice-cold buffer and either immediately lysed or incubated at $37^{\circ} \mathrm{C}$ for $24 \mathrm{hr}$. The autoradiogram in Figure 6 shows that T4 endonuclease treatment decreased the amount of the restriction fragments that contained either the Ecogpt or alpha sequences ( 1 anes $a$ and $b)$. The frequencies of ESS in the tho I fragments were calculated from the proportion of fragments insensitive to the T4 endonuclease using the Poisson expression and were normalized to a fragment size of $100 \mathrm{~kb}$ (Table 2). These data indicate that approximately the same frequency of ESS are produced in the fragments which carry either the Ecogpt or alpha sequences (2.85 vs. 2.5 ESS per $100 \mathrm{~kb}$ per $5 \mathrm{~J} / \mathrm{m}^{2}$ ).

When the cells are incubated for $24 \mathrm{hr}$ following UV irradiation (Figure 6 , lanes $c$ and $d$ ), there is a significant reappearance of T4 endonucleaseresistant Xho I fragments. From the frequency of ESS in these fragments (Table 2), it appeared that approximately $96 \%$ of the ESS were removed from those fragments which contain the Ecogpt genes. In contrast, only $62 \%$ of the ESS were removed from those fragments containing alpha sequences. Thus, consistent with our finding using the immunological method, the alpha sequences do not appear to be repaired as efficiently as the Ecogpt genes.

\section{DISCUSSION}

An immunological method was used to isolate DNA fragments containing repair patches from total genomic DNA. The separation was dependent on the number of fragments containing repair patches as evidenced by the linear response with either the dose of UV to the cell or with the post-UV 
incubation time. While the percentage of total DNA bound by the antibody was dependent on the fragment size, the percentage of repair patches detected by the antibody was independent of fragment size for DNA fragments as small as 200 bp. This is probably due to the fact that the size of the repair patch following UV irradiation is considerably smaller than the smallest DNA fragments used $(11,13)$. UV produces repair patches that are on average 20 $b p$, while $A F B_{1}$ produces repair patches that are a mixture of 20 bp and $10 \mathrm{bp}$ (11). This is presumably because separate repair pathways are acting on the bulky $\mathrm{AFB}_{1}$ adducts and the apurinic sites produced by the spontaneous loss of adducts from the DNA. It is not known what effect the size of the repair patch has on the efficiency of antibody binding; however, efficient binding of the antibody to DNA from cells exposed to ionizing radiation, which should produce small repair patches of 10 bp or less, has also been observed (Leadon, unpublished results). Thus, the antibody appears to be able to recognize and bind repair patches of relatively short length. The number of antibody molecules bound to a repair patch and the number of antibody molecules required to precipitate a DNA fragment of a given size are, as yet, unknown. However, it is apparent that only one repair patch is required to cause precipitation of a DNA fragment when that fragment is relatively small.

The isolation of DNA fragments containing repair patches allows for the quantitation of repair of a variety of types of DNA damage in the genome overall. In addition, a comparison of the processing of damage between various sequences in the genome can be made by hybridizing this DNA to probes for the specific sequences. The repair of damage in a sepecific nucleotide sequence was investigated by comparing the proportion of the Ecogpt sequence contained in DNA fragments bound by the antibody with the total amount of DNA bound by the antibody. Following exposure to either UV or $A_{F} B_{1}$, a greater percentage of the Ecogpt sequences were found in DNA fragments bound by the antibody than there was total DNA bound by the antibody, indicating a preferential repair in regions of the genome containing these sequences compared to the genome overall. We compared our finding of preferential repair in the Ecogpt gene to repair in alpha DNA analyzed by the immunological method, since repair in alpha DNA has been extensively characterized by other methods. In contrast to the results with Ecogpt, the proportion of alpha sequences in the antibody-bound DNA fragments was similar to the proportion of total DNA bound by the antibody following UV irradiation, indicating that UV damage in those fragments containing alpha sequences was repaired with the same efficiency as in the genome overall. 
However, following treatment with $\mathrm{AFB}_{1}$, a much lower percentage of the alpha sequences was found in the DNA fragments bound by the antibody compared to total DNA.

The observation that repair of UV damage in the alpha sequences was as efficient as in the genome overall while repair of $\mathrm{AFB}_{1}$ damage was deficient is consistent with results of previous studies which used different methodology (11-14). The deficient repair of $\mathrm{AFB}_{1}$ damage in alpha DNA was hypothesized to be due to the chromatin conformation of a non-transcribed, heterochromatic DNA, since there was no difference in the level of adduct binding. The fact that UV damage in alpha DNA is proficiently repaired might then be explained by pyrimidine dimer-induced alterations of the alpha chromatin structure in such a way as to facilitate its repair.

The preferential repair of UV damage in the Ecogpt gene compared to the alpha sequences is not due to a difference in the initial level of pyrimidine dimers, since the efficiency of their formation (measured by ESS) was similar for the two sequences. This indicates that the gene is not significantly shielded from the UV and eliminates the possibility that the increased repair synthesis in the Ecogpt gene might be related to a greater dimer frequency in these sequences. The observation that active genes are more susceptible than other regions of the genome to modification by benzo(a)pyrene (6) and $A_{1}$ $(15,33)$ does, however, complicate the interpretation of the more efficient repair of $\mathrm{AFB}_{1}$ in the Ecogpt gene. The use of $\mathrm{T} 4$ endonuclease $V$ to measure the repair of pyrimidine dimers in specific sequences has been developed by Hanawalt and co-workers $(17,34,35)$. We compared that assay and the immunological method for analyzing repair within specific sequences (Tables 1 and 2). Using both these methods, we observed a preferential repair of UV damage in the Ecogpt gene. However, the immunological method has the dual advantage of allowing measurement of repair following exposure to more than one damaging agent (e.g., UV and $A F B_{1}$ ) and of allowing comparison of repair in total DNA and in specific sequences in the same DNA preparation. In addition, the sensitivity of this assay for measuring repair in a specific sequence is not dependent on the size of the restriction fragment that contains the sequence of interest, as is the case with measuring ESS.

The preferential repair of damage in DNA fragments containing the Ecogpt gene observed in this study may be due to the chromatin structure associated with an expressed gene. However, confluent cultures were used in these experiments and it is not known what the transcriptional state of the gene is under these conditions. If the gene is not being transcribed or only to a 
small extent, then the 3-4 fold increase in repair observed in DNA fragments containing the Ecogpt genes compared to that in the genome overall might be further enhanced if repair were examined under conditions in which the gene is actively transcribed. Efficient removal of pyrimidine dimers has been observed in the dihydrofolate reductase (DHFR) gene in CHO cells under conditions where the gene is both actively transcribed and amplified (17). This result does not appear to be dependent on the amplification state but on the transcriptional activity of the gene, since a sequence $5^{\prime}$-upstream to the DHFR gene which is not transcribed but still within the amplification unit exhibits the inefficient removal of dimers characteristic of the genome overall in CHO cells. Moreover, efficient repair is still found in the DHFR gene even when it is not amplified (34). The altered chromatin structure associated with actively expressed genes in these cells may facilitate the repair of DNA lesions. Recently, Cohn and Lieberman $(19,20)$, using a similar immunological method for the isolation of DNA sequences containing BrUra, have shown that there is a nonrandom distribution of repair patches with doses of greater than $6 \mathrm{~J} / \mathrm{m}^{2}$ UV for up to $36 \mathrm{~h}$ postirradiation in confluent human cultures. This nonrandom distribution of repair patches at early times may also reflect a more rapid repair of specific DNA sequences.

An alternate explanation for the proficient repair of damage in DNA fragments containing the Ecogpt genes is that it may be related to an altered chromatin structure associated with integration of the plasmid. Weintraub (36) has shown that an SI nuclease sensitive site located on the $B$-globin gene was retained after transfection of the $5^{\prime}$-end of the chicken $\beta^{A}-g$ lobin sequence into mouse $L$ cells, whereas the inactive endogenous mouse $\alpha-g$ lobin genes were not S1 sensitive. This suggests that while transfected DNA may be able to circumvent the normal suppression of certain genes that occurs during development, the transfected gene still retains some of the characteristics of the endogenous sequence. We are currently investigating the repair of damage both in endogenous genes and in cell lines that contain an integrated gene with an inducible promoter in order to better distinguish enhanced repair of a sequence due to its transcriptional activity from enhanced repair due to chromatin alterations brought about by integration of a sequence into the genome.

\section{ACKNOWLEDGEMENTS}

I thank Philip $C$. Hanawalt for encouragement, generosity in providing lab space, and financial support: C.A. Smith, P.K. Cooper and P.C. Hanawalt for 
critical reading of the manuscript; $M$. Vanderlaans and $J$. Gray for the monoclonal antibody against bromodeoxyuridine; and M. Singer for pCA1004a.

This work was supported by a grant (NP161) from the American Cancer Society, a USPHS grant GM09901 awarded to P.C. Hanawalt and a PHS grant CA40453 awarded by the National Cancer Institute, DHHS, to S.A. Leadon.

*Present address: Lawrence Berkeley Laboratory, Building 934, University of California, Berkeley, CA 94720, USA

\section{REFERENCES}

1. Garel, A. and Axel, R. (1977) Proc. Natl. Acad. Sci. USA 74, 4876-4871.

2. We intraub, H. and Groudine, M. (1976) Science 193, 848-856.

3. Davies, R.L., Fuhrer-Krusi, S. and Kucherlapati, R.S. (1982) Cell 31, 521-529.

4. Brutlag, D.L. (1980) Ann. Rev. Genet. 14, 121-144.

5. Bailey, G.S., Nixon, J.E., Hendricks, J.D., Sinnhuber, R.0. and Van Holde, K.E. (1980) Bi ochemi stry 19, 5836-5842.

6. Leadon, S.A., Amstad, P.A. and Cerutti, P.A. (1983) in the Proceedings of the NATO Advanced Study Institute on "The use of human cells for the assessment of risk from physical and chemical agents", Castellani, A. ed., Vol. 60, pp. 105-117, Plenum Press, New York.

7. Cech, T. and Pardue, M.L. (1977) Cell 11, 631-630.

8. Weisenhahn, G.P., Hyde, J.E. and Hearst, J.E. (1977) Biochemistry 16, 925-932.

9. Zolan, M.E., Smith, C.A., Calvin, N.M., and Hanawalt, P.C. (1982) Nature $299,462-464$.

10. Kaneko, M. and Cerutti, P.A. (1980) Cancer Res. 40, 4313-4319.

11. Leadon, S.A., Zolan, M.E. and Hanawalt, P.C. (1983) Nucleic Acids Res. 11 , 5674-5689.

12. Leadon, S.A. and Hanawalt, P.C. (1984) Carcinogenesis 5, 1505-1510.

13. Zolan, M.E., Cortopassi, G.A., Smith, C.A. and Hanawalt, P.C. (1982) Cell $28,613-619$.

14. Zolan, M.E., Smith, C.A. and Hanawalt, P.C. (1984) Biochemistry 23, 63-69.

15. Irvin, R.T. and Wogan, G.N. (1984) Proc. Natl. Acad. Sci. USA 81, 664-668.

16. Arrand, J.E., and Murray, A.M. (1982) Nucl. Acids Res. 10, 1547-1555.

17. Bohr, V.A., Smith, C.A., Okumoto, D.S. and Hanawalt, P. C. (1985) Cell 40, 359-369.

18. Nose, K. and Nikaido, 0. (1984) Biochim. Biophys. Acta. 781, 273-278.

19. Cohn, S.M. and Lieberman, M.W. (1984) J. Biol. Chem. 259,12456-12462.

20. Cohn, S.M. and Lieberman, M.W. (1984) J. Biol. Chem. 259 , 12463-12469.

21. Mulligan, R.C. and Berg, P. (1981) Proc. Natl. Acad. Sci. USA 78 , 2072-2076.

22. van Zeeland, A.A., Smith, C.A. and Hanawalt, P.C. (1981) Mutat. Res. 82, 173-189.

23. Leadon, S.A., Tyrrell, R.M. and Cerutti, P.A. (1981) Cancer Res. 41 , 5125-5129.

24. Leadon, S.A. and Cerutti, P.A. (1982) Anal. Biochem. $120,282-288$.

25. Smith, C.A., Cooper, P.K. and Hanawalt, P.C. (1981) in DNA Repair: A Laboratory Manual of Research Procedures, Friedberg, E.C. and Hanawalt, P.C. eds., Vol. 1, pp. 289-305, Marcel Dekker, New York.

26. Gratzner, H.G. (1982) Science 218, 474-475. 
27. Aarden, L.A., Lakmaker, F. and Feltkamp, F.E.W. (1979) J. Immunol. Methods $10,27-37$.

28. Southern, E.M. (1975) J. Mol. Biol. 98, 503-517.

29. Wahl, G.M., Stern, M. and Stark, G.R. (1979) Proc. Natl. Acad. Sci. USA 76, 3683-3687.

30. Thayer, R.E., Singer, M.F. and McCutchan, T.F. (1981) Nucleic Acids Res. $\underline{9}$, 169-181.

31. Seawel1, P.C., Friedberg, E.C., Ganesan, A.K. and Hanawalt, P.C. (1981) in DNA Repair: A Laboratory Manual of Research Procedures, Friedberg, E.C. and Hanawalt, P.C. eds., Vol. 1, pp. 289-305, Marcel Dekker, New York.

32. Nakabeppu, Y. and Sekiguchi, M. (1981) Proc. Natl. Acad. Sci. USA $\underline{78}$, 2742-2746.

33. Yu, F. (1983) Carcinogenesis 4, 889-893.

34. Bohr, V.A., Okumoto, D.S. and Hanawalt, P.C. (1986) Proc. Natl. Acad. Sci. USA 83, 3830-3833.

35. Madhani, H.D., Bohr, V.A. and Hanawalt, P.C. (1986) Cell 45, 417-423.

36. We intraub, H. (1983) Cell 32, 1191-1203. 